Review

\title{
Recombinant Spider Silks-Biopolymers with Potential for Future Applications
}

\author{
Martin Humenik ${ }^{\dagger}$, Andrew M. Smith ${ }^{\dagger}$ and Thomas Scheibel * \\ Lehrstuhl für Biomaterialien, Gebäude FAN/D, Universität Bayreuth, Universitätsstraße 30, 95447, \\ Bayreuth, Germany; E-Mails: martin.humenik@bm.uni-bayreuth.de (M.H.); \\ andrew.smith@bm.uni-bayreuth.de (A.M.S.) \\ * Author to whom correspondence should be addressed; E-Mail: thomas.scheibel@ bm.uni-bayreuth.de; \\ Tel.: +49-(0)921-55-7360/61 (Sekr.); Fax: +49-(0)921-55-7346. \\ $\dagger$ Contributed equally.
}

Received: 17 December 2010; in revised form: 12 February 2011 / Accepted: 14 March 2011 / Published: 17 March 2011

\begin{abstract}
Nature has evolved a range of materials that compete with man-made materials in physical properties; one of these is spider silk. Silk is a fibrous material that exhibits extremely high strength and toughness with regard to its low density. In this review we discuss the molecular structure of spider silk and how this understanding has allowed the development of recombinant silk proteins that mimic the properties of natural spider silks. Additionally, we will explore the material morphologies and the applications of these proteins. Finally, we will look at attempts to combine the silk structure with chemical polymers and how the structure of silk has inspired the engineering of novel polymers.
\end{abstract}

Keywords: spider silk; biopolymer; recombinant

\section{Introduction}

In nature a wide range of materials have properties desirable for man-made applications. One such material that has been exploited by man for millennia is silk [1,2], which is produced by various arthropods [3,4]. For textile applications, silk from the larvae of the moth Bombyx mori (silkworms) is processed on a large scale in silkworm farms. Silk from spiders has also been utilized throughout 
history, but has never been exploited on an industrial scale [5]. Of note, many spider silks have better mechanical properties than silkworm's silk [6]. The different properties are due to the different natural functions of the material. Silkworms use their silk for protection during their metamorphosis, while many spiders use silk to catch prey. Of particular interest are the silks from spiders that produce orb webs which are used to catch aerial prey. The silk in these webs needs to be capable of capturing and holding the spider's flying prey, which requires interplay of various silks with different properties. Female orb weaving spiders can produce up to seven different silks which have a range of properties. The most extensively characterised of which is Major Ampullate silk (MA silk), and therefore we will focus on this silk in this review. Here, we will discuss the current understanding of the specific properties of spider silk and how researchers are attempting to use this knowledge to develop new materials. We will cover the production of recombinant spider silks and their processing into various material morphologies. Additionally we will look into attempts to modify spider silk either genetically or chemically to incorporate new functions. Lastly, the question of how silk has inspired the development of polymeric materials that mimic its molecular structure for applications will be addressed.

\subsection{Silk Structure}

All spider silks are made up of proteins that are more commonly termed spidroins. The MA silk of the most studied spider genera Nephila, Argiope, Latrodectus and Araneus consists of two proteins called Major ampullate spidroin 1 and 2 (MaSp1 and 2). Spidroins share several common features such as a core sequence, comprising highly repetitive amino acid motifs, flanked by non-repetitive carboxyl- (C-) and amino- (N-) terminal domains [7,8]. Additionally, these spidroins have a high molecular weight, 200 to $350 \mathrm{kDa}$ or even larger [9-11]. The spidroins are covalently linked via cysteine bridges in their termini and undergo further oligomerization due to their repetitive regions [12]. The repetitive regions have an unusual amino acid composition with more than 50\% alanine (A) and glycine $(\mathrm{G})$ residues. The repetitive regions of MaSp1 consists of repeats of a few GA motifs linked to poly-alanine sequences $(A)_{n}(n=4-12)$ that are followed by several GGX $(X=Y, L$ and Q) motifs. MaSp2 also contains poly-alanine stretches, but typically has a higher content of proline residues, reflecting the fact that the GGX motif is alternated with the GPGXX motif, (X = Q, G, Y) [8] (Table 1). These short motifs have been shown to be clustered into ensemble repeats consisting of 20-40 residues where the glycine rich region is terminated by poly-alanine stretches [13-15]. Interestingly, if just the proline content is taken into consideration, the two main spidroins of the European garden spider Araneus diadematus, which due to historical reasons are termed A. diadematus fibroin 3 and 4 (ADF3 and 4), are analogues of $N$. clavipes MaSp2 (Table 1) [16]. This finding would indicate a severe difference between MA silks of different species; however, similarities between MA silks of different species are higher when hydropathicity of these spidroins is considered. Detailed analysis reveals MaSp1/ADF4 to be more hydrophobic while MaSp2/ADF3 have more hydrophilic amino acid residues [17], indicating that the main proteins of Ma silk reflects a hydrophilic/hydrophobic pair.

Secondary structure studies of the MA silk fiber indicate that poly-alanine stretches are in an anti-parallel $\beta$-sheet conformation forming crystalline domains with sizes of approximately 2 by 5 by $7 \mathrm{~nm}$ [18-21]. However, only $40 \%$ of poly-alanine $\beta$-sheets in silk fibers are highly ordered while 
the other $60 \%$ exist as poorly aligned $\beta$-sheet regions [22,23]. The GPGXX and GGX sequences form an amorphous region of protein folds that surrounds the crystalline regions of $\beta$-sheets (Figure 1) [24]. The secondary structure of the GPGXX pentapeptide motif is well understood $[25,26]$. The GPGXX motif likely forms $\beta$-turns, and in the case of successive repetition a spiral is formed, as suggested for elastin $[27,28]$. NMR studies have shown that a fraction of $(\mathrm{GA})_{\mathrm{n}}$ and GGX motifs in major ampullate silk are in $\beta$-sheet as well as less ordered helical structures [23,27].

Table 1. Repetitive motifs and corresponding secondary structures as present in N. clavipes and A. diadematus MA silk (data taken form [105]).

\begin{tabular}{|c|c|c|c|c|c|}
\hline Spider & $\begin{array}{l}\text { MA silk } \\
\text { protein }\end{array}$ & $(\mathrm{A})_{\mathrm{n}} /(\mathrm{GA})_{\mathrm{n}}$ & $\int_{30 \text {-helix }}^{\text {GGX }}$ & GPGXX & C- /N-terminus \\
\hline \multirow{2}{*}{ Nephila clavipes } & MaSp1 & & & & \\
\hline & MaSp2 & & & & \\
\hline \multirow{2}{*}{ Araneus diadematus } & ADF3 & 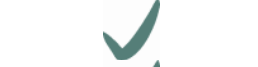 & & & \\
\hline & ADF4 & & & & \\
\hline
\end{tabular}

Figure 1. Schematic representation of the hierarchical structure of a spider MA silk fiber. On the macroscopic level, the skin-core structure can be recognized [106] and on the sub-microscopic level, the presence of the aligned fibrils has been shown [107]. The nanoscopic structure is represented by poly-Ala $\beta$-sheet crystals aligned with the fiber axis and embedded in the amorphous phase, comprising GPGXX and GGX ensemble repeats $[108,109]$.

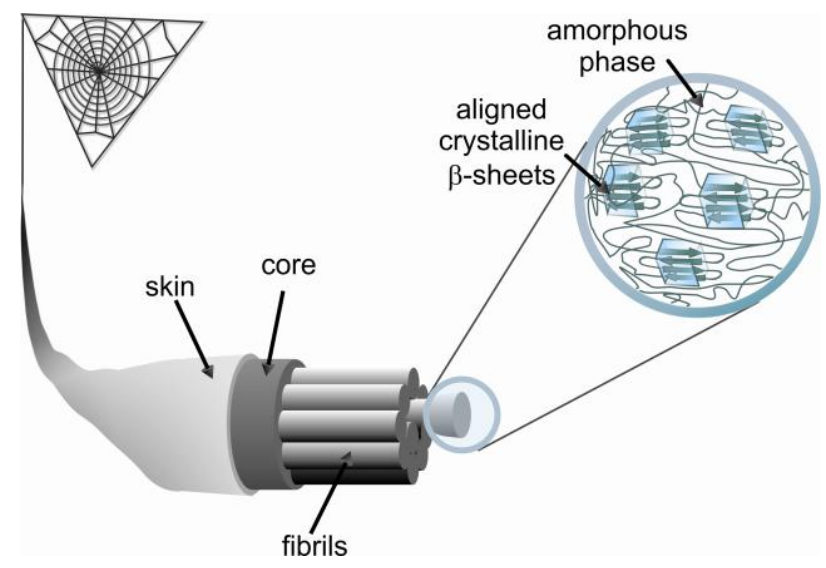

Spider silk is famed for its mechanical strength. As an example, MA silk fibers of $A$. diadematus have strength in the range of high-tech fibrous materials (Table 2). Most importantly the toughness of spider silk is a lot higher than that of man-made fibers based on its low density, $1.3 \mathrm{~g} . \mathrm{cm}^{-3}$ compared to e.g., 7.8 g.cm ${ }^{-3}$ of steel [29]. During applied strain major ampullate silk fibers exhibit a stiffening phase quickly followed by a yield point related to material softening, followed by a second stiffening phase. A short softening regime can also be observed immediately prior to failure. If the fiber is relaxed before it breaks, viscoelastic behavior is observed indicating the presence of a small plastic component (Figure 2) [30]. 
Table 2. Comparison of the mechanical properties of $A$. diadematus MA silk fibers and other natural and synthetic fibers (data taken from [6,29]).

\begin{tabular}{lccccc}
\hline Material & $\begin{array}{c}\text { Density } \\
{\left[\mathrm{g} . \mathrm{cm}^{-3}\right]}\end{array}$ & $\begin{array}{l}\text { Strength } \\
{[\mathrm{GPa}]}\end{array}$ & $\begin{array}{l}\text { Stiffness } \\
{[\mathrm{GPa}]}\end{array}$ & $\begin{array}{c}\text { Extensibility } \\
{[\%]}\end{array}$ & $\begin{array}{l}\text { Toughness } \\
{\left[\mathrm{MJ}^{\mathrm{m}} \mathrm{m}^{3}\right]}\end{array}$ \\
\hline A. diadematus MA silk & 1.3 & 1.1 & 10 & 27 & 180 \\
Nylon fiber & 1.1 & 0.95 & 5 & 18 & 80 \\
Bombyx mori silk (Mulberry silkworm) & 1.3 & 0.6 & 7 & 18 & 70 \\
Kevlar 49 ${ }^{\mathrm{TM}}$ fiber & 1.4 & 3.6 & 130 & 2.7 & 50 \\
Carbon fiber & 1.8 & 4 & 300 & 1.3 & 25 \\
High-tensile Steel & 7.8 & 1.5 & 200 & 0.8 & 6 \\
\hline
\end{tabular}

Figure 2. Typical stress-strain curve for a spider MA silk fiber collected from an adult A. diadematus female at reeling speed of $20 \mathrm{~mm} / \mathrm{s}$ (for typical values see Table 2). The initial elastic phase provides the Young's modulus (approx. $10 \mathrm{GPa}$ ), expressing the stiffness of the fiber. This area corresponds to the breaking of hydrogen bonds interconnecting so called worm-like chains (WLCs) in the amorphous phase. Softening of the material after the hydrogen bonds were broken (yield point) corresponds to the further extension of WLCs, which behave as entropic springs. The following second stiffening phase corresponds to the breaking of hydrogen bonds within the crystalline phase of $\beta$-sheets. The overall toughness of the fiber is comparable to the total energy of the hydrogen bonds formed within the amorphous and the crystalline phase. Breaking of the hydrogen bonds upon fiber stretching is irreversible in the amorphous phase and reversible in the crystalline phase (stick-slip phenomenon) and represents a plausible mechanism for energy dissipation [109-113].

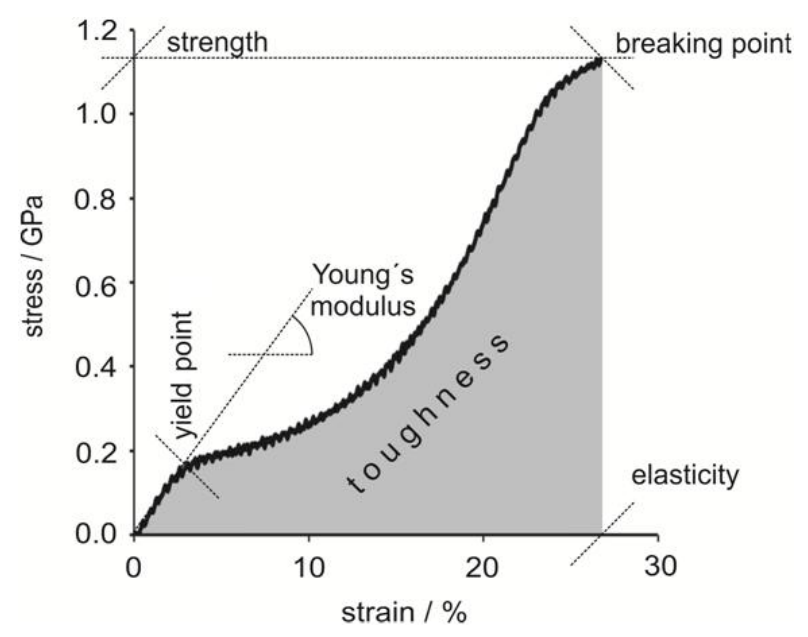

\subsection{A Lack of Natural Sources for Spider Silk}

Spiders produce a wide range of high performance silks which are interesting for many applications, but farming spiders is problematic since most spiders are not social creatures, even being cannibalistic. Like large scale farming, collecting silk from spiders can be difficult and time consuming due to the variety of different silk types which can hardly be separated (except MA silk). Silkworms, in contrast, can easily be farmed and their silk is simply harvested from the cocoons making silkworm silk collection straight forward. Recent developments in biotechnology have tempted 
researchers to transfer spider silk genes to host organisms for recombinant protein production. There have been two general biotechnological routes by which silk proteins have been produced, firstly expression of natural spidroin genes (or fragments thereof) and secondly the engineering of new genes encoding proteins that mimic the essential parts of spidroins (Figure 3) [31].

Figure 3. Biotechnological production of recombinant spider silk proteins. (A) Structures of MA silk repetitive motifs are available from experimental studies using NMR, FT-IR, Raman spectroscopy and X-ray diffraction techniques; (B) Information on MA protein sequences are available from cDNA libraries; (C) Based on A and B synthetic genes can be designed suitable for recombinant expression in traditional host organisms; (D) Engineered spidroins can be recombinantly produced e.g., in bacteria such as E. coli using synthetic silk genes [114]; (E) Amino acid sequences of designed silk modules A, Q and C are derived from the known sequences of the dragline silk proteins ADF4 and ADF3. The amino acid sequence is back translated into nucleotide sequences using the bacterial codon usage. These repeat units are multimerized to generate synthetic genes coding for the engineered proteins eADF4 and eADF3 [50].

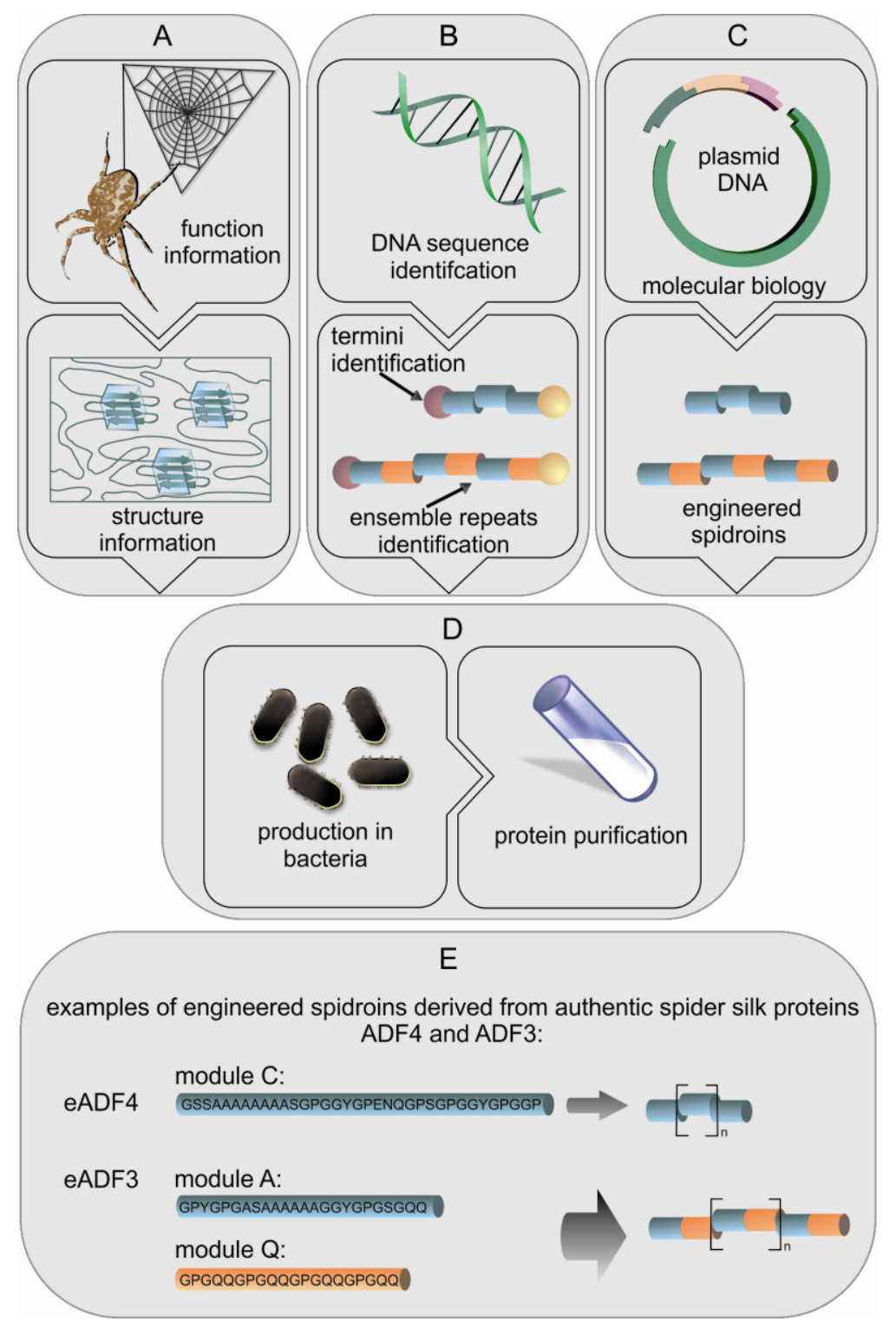




\section{Recombinant Spidroins}

\subsection{Recombinant Production of Spidroins from cDNA}

Typically, recombinant protein production depends on a gene encoding a protein from one organism being transferred into a production host such as the bacterium Escherichia coli. However, in the case of spidroins, which are large repetitive proteins, the expression of the natural genes in several traditionally employed hosts creates some problems. The main issue is the DNA codon usage of spiders, i.e., the prevalence of specific codons for each amino acid, which is different to that of bacteria and yeasts. Spidroin genes have an extreme codon bias, with only a subset of available codons being used [11]. A further complication is the issue of homologue recombination in many hosts, which removes repetitive sequences. As a consequence, attempts to express MaSp1 genes in E. coli has resulted in extremely low yields of the intended protein, and additional attenuated protein sequences being produced [32]. It is known that spiders produce silk gland specific pools of tRNAs for glycine and alanine to specifically deal with the bias in amino acids [33]. One solution to this problem is over-expression of the gene glyVXY in bacterial hosts encoding tRNAs for the triplets GGU and GGC. With such increased tRNA ${ }^{\text {gly }}$ levels, it is possible to achieve much higher silk gene expression levels e.g. in E. coli. The largest MaSp1 construct tested in such $E$. coli consisted of 96 copies of its repeating module giving a protein with a molecular weight of $285 \mathrm{kDa}$ [34]. Thus it is now possible to bacterially produce spidroins with a size similar to that of natural spider silk proteins, and sufficient yields [12].

Alternatives to bacterial expression have also been tested. Fragments of MaSp1 and 2 have been produced in mammalian cell lines, namely bovine mammary epithelial alveolar cells and baby hamster kidney cells. Both of these cell lines have successfully managed to secrete 110 and $140 \mathrm{kDa}$ silk proteins, however, the yields dramatically decreased as the size of the protein increased. [35] This may be related to a range of factors including inefficient transcription, low gene copy numbers, or a limitation of the cellular systems to cope with such large proteins [32].

The baculovirus expression system has been used in combination with the insect cell line sf9 to express partial genes for ADF3 and 4 [17]. This has been carried further through the use of silkworms as production hosts; as these are natural silk producers they should have the capacity to deal with the large spider silk proteins. Silkworms have been infected with a baculovirus containing a MaSp1 fragment $(70 \mathrm{kDa})$, producing reasonable yields up to $3 \%$ of the total soluble protein in the BmN cells of silkworms [36]. A more recent approach is the first example of transgenic B. mori silkworms, which have been transformed with an $83 \mathrm{kDa}$ fragment of the MaSp1 gene from $N$. clavata. This fragment was inserted into a vector with the silkworm sericin 1 promoter to control expression of the fragment and to ensure its incorporation into the silk of the cocoon. This vector was then injected into silkworm embryos, and successful transgenic individuals were mated to generate G2 descendants. The MaSp1 fragment was found in the sericin layer surrounding the silk fibers of these transgenic silkworms [37].

\subsection{Recombinant Production of Engineered Spidroins with Adapted DNA Sequences}

The above mentioned approaches have attempted to express fragments of natural spider genes. However, engineering of genes adapted to specific hosts is possible as the amino acid sequences of MaSp and flagelliform silk are highly repetitive and based on short motifs (e.g., $A_{n}$, GPGXX). The 
motifs form specific modules of approximately 30 amino acids which are repeated up to 100 times, and these repeated modules form the core domain of spidroins. The modules are highly conserved within the respective silks due to intragenic concerted evolution [9]. As such, it is easy for researchers to identify the repeats and create new artificial genes encoding such repeats (Figure 3(E)). Basically short DNA oligonucleotides are designed that encode the various modules of a specific spidroin. These oligonucleotides are then ligated to generate a sequence that is reminiscent of the core sequence of a spidroin. Thus, engineered genes with various sizes can be made allowing easy testing of the effect of e.g., protein size and sequence on the function of an individual spidroin. In the literature, the vast majority of studies employ the sequences from MaSp1 and 2 of $N$. clavipes, or the sequences for ADF3 and 4 from A. diadematus, but some have used the flagelliform repeats of $N$. clavipes [38-40]. The production host most often used is E. coli, but there are also studies using plants as well as eukaryotic cells and transgenic animals. In one example of spidroin production in plants, 18 short oligonucleotides encoding different repeat units from $N$. clavipes were assembled into six short fragments which could then be ligated to create synthetic spidroin genes of various sizes. The genes were transferred to tobacco and potato plants. Production yields from these plants reached levels in excess of $2 \%$ of the total soluble protein. The recombinant silk protein could easily be purified by a combination of heat treatment, acidification and ammonium sulfate precipitation $[35,41]$. In addition to tobacco and potatoes another engineered spidroin based on MaSp1 from Nephila clavipes was produced in the seeds of Arabidopsis, yielding 18\% of the desired engineered spidroin within the total soluble protein, which makes this a viable means of protein production $[42,43]$.

Engineered spidroins have been developed based on ADF3 and ADF4 from A. diadematus [44,45]. In these engineered spidroins individual modules ( $\mathrm{A}, \mathrm{Q}$, and $\mathrm{C}$ ) have been designed in a way that multiple units can easily be combined allowing the production of spidroins with various specific lengths. The modules A and Q can be combined to produce a mimic of the ADF3 sequence, while the $\mathrm{C}$ module is the basic module of the repetitive region of ADF4 (Figure 3(E)). Additionally, it is possible to enclose the coding sequences with the native $\mathrm{N}$ - and $\mathrm{C}$-terminal domains, allowing the study of the effect of these terminal regions on self-assembly [45-49]. These spidroins are recombinantly produced in E. coli, and the soluble proteins can easily be purified using a heat step, followed by an ammonium sulfate precipitation similar to the method used to purify the engineered spidroins from plants [41]. With fermentation methods for the growth of E. coli it is possible to get protein yields up to $360 \mathrm{mg} / \mathrm{L}$, allowing the easy production of large quantities of recombinant spidroins [50].

\subsection{Processing of Recombinant Spidroins into Fibers}

In this paragraph we will describe the generation of artificial spinning dopes of recombinant spidroins for the production of fibers, and how the fibers compare to natural spider silk fibers. A technically easy method is the processing of recombinant spidroins from hexafluoroisopropanol (HFIP) solutions. The recombinant spidroin is dissolved in HFIP at a concentration in the order of $25-30 \%(\mathrm{w} / \mathrm{v})$ and then extruded through a needle into a coagulation bath e.g., of $90 \%$ isopropanol [31]. However, the physical properties of such fibers are always orders of magnitudes lower than seen in the natural material [51]. Within the spider it is known that the initial spinning dope 
is an aqueous solution with up to $50 \%(\mathrm{w} / \mathrm{v})$ protein solution, and that during passage along the spinning duct there is a change of ions, a lowering of the $\mathrm{pH}$ and also the application of shear forces. Therefore, an alternative is to use an aqueous solvent rather than organic solvents. This process utilizes the spidroins natural properties to self-assemble by mimicking the process that occurs within the spider. This involves a number of factors, firstly a starting solution with a protein concentration higher than $15 \%(\mathrm{w} / \mathrm{v})$. The solubility of a protein in water is affected by the presence of ions. Low concentrations of salts tend to improve the solubility of proteins, due to the formation of ion-rich hydration layers in the vicinity of charged and polar amino acid residues (as described by the Debye-Hückel theory). High concentrations of salt can contribute to protein solubilization (known as 'salting in') or have the opposite effect, causing the protein to precipitate (known as 'salting out'). The magnitude of both effects is dependent upon the particular ions. According to Hofmeister`s studies in the early 20th century, chaotropic ions stabilize soluble proteins, whereas kosmotropic ions promote structure formation and protein aggregation [52-54]. It has been demonstrated that in the absence of chaotropic ions (for example, using deionized water) and at subcritical protein concentrations (the proteins are completely in solution), a liquid-liquid phase separation takes place, resulting in an increased protein concentration in a high density phase consisting of large colloidal assemblies without detectable secondary structure. Kosmotropic ions (e.g., ammonium sulfate, potassium phosphate) reduce hydration of a polypeptide by partial polarization of water molecules that are hydrogen bonded to amide moieties among other effects [55]. Assuming that spider silk proteins are to be intrinsically unfolded in aqueous solution, the presence of kosmotropic ions promotes intramolecular interaction of the polypeptide backbone and thus may trigger assembly [56]. In contrast, the presence of chaotropic salts (e.g., sodium chloride) inhibits aggregation and assembly of the silk proteins and even prevents liquid-liquid phase separation. Chaotropic salts tend to interact directly with polypeptide backbones thus favoring 'salting in' [29].

Using partial genes of ADF3 and ADF4 it was found that ADF3 was solubly produced, however, ADF4 formed filaments within insect cells, used as production hosts. After purification of ADF4 followed by denaturation with guanidinium thiocyanate, a subsequent renaturation did not yield filaments in vitro indicating that the cellular environment, salts and $\mathrm{pH}$, of the employed insect cells was required for assembly.

Engineered homologues to these proteins were studied using micro-fluidics to determine the effect of solvent changes and shear forces on the formation of spidroin fibers. It was shown that the more hydrophobic engineered spidroin eADF4 (47 kDa, comprising only part of the repetitive domain) formed spherical particles, while the more hydrophilic eADF3 (106 kDa, comprising parts of the repetitive domain and the carboxyl-terminal non-repetitive domain) formed fibers under defined environmental conditions. However, eADF4 could be incorporated into the eADF3 threads if the proteins were mixed prior to phase separation [45]. This study highlighted the requirement of simultaneous shear forces and a $\mathrm{pH}$ switch to initiate fiber assembly.

Aggregation of spidroins and the effect of shear forces have been explored further in recent studies on the role of the C-terminal domain on the assembly of spidroins. eADF3 with a C-terminus is more prone to aggregation while a similar sized protein without a $\mathrm{C}$-terminal domain is less prone to aggregation. It can be shown that the C-terminus of eADF3 further increases the aggregation propensity of the protein under shear stress. As a consequence it is possible to produce long fibrillar 
structures with aligned $\beta$-sheets, as detected by polarized FTIR. In contrast, in the absence of the C-terminus only poorly-defined $\beta$-sheet aggregates are formed with no alignment [46]. Solving the soluble NMR structure of the C-terminus has helped to explain certain effects. The C-terminus is a dimeric parallel five helix bundle, which is stabilized in the presence of sodium chloride. It is proposed that this acts to correctly position the repetitive regions so that ordered fibrous assemblies can be formed [48]. Additionally, the N-terminal domain has been shown to be a dimeric five-helix bundle, but in this case arranged in an anti-parallel fashion [57]. The $\mathrm{N}$-terminal domain dimerizes as the $\mathrm{pH}$ of the solution is reduced from $\mathrm{pH} 7.2$ to 6.0 , which implies that the $\mathrm{N}$-terminus is highly sensitive to the $\mathrm{pH}$ changes that occur in the spider's spinning gland [49,57].

\section{Processing of Recombinant Spidroins into Other Morphologies}

In addition to fibers, spidroins can be processed into a diverse set of morphologies (Figure 4(A)). The processing of spider silk proteins can be accomplished from aqueous solutions or organic solvents, and together with conditions such as $\mathrm{pH}$, temperature, protein concentration, ionic strength and composition, the assembly of the spidroins can be influenced. Thereby the $\beta$-sheet content and alignment of $\beta$-sheet crystallites vary, which directly influences the function of the obtained materials. According to the versatile combination of aforementioned conditions hydrogels, microspheres, non-wovens, capsules and films have been successfully produced and intensively studied.

Figure 4. Processing of recombinant spider silk proteins into various non-natural shapes; (A) Apart from the natural MA silk fiber (1) produced by a spider, other morphologies such as films (2), capsules (3), microspheres (4) and hydrogels (5) can be prepared from recombinant spidroins; (B) Control over the formation of nanofibrils and microspheres: At low potassium phosphate concentrations nanofibrils self-assemble, while at high salt concentrations microspheres are formed. At intermediate phosphate concentrations the two species coexist [53].

A

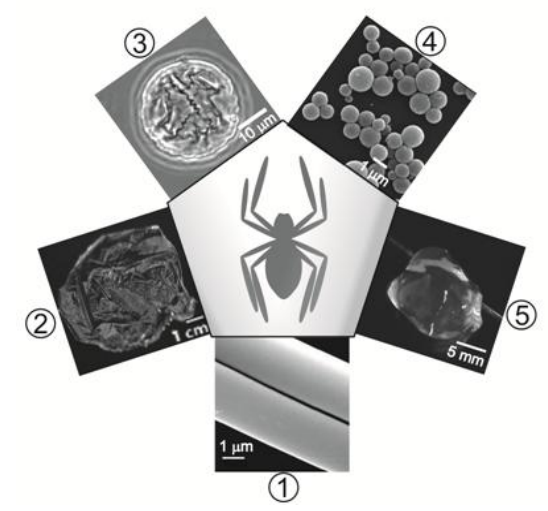

B

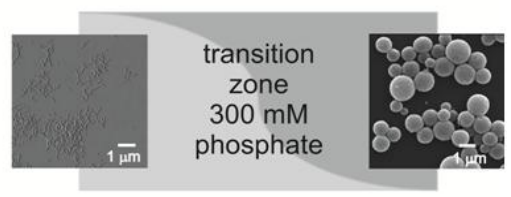

\subsection{Hydrogels Made from eADF4}

To our knowledge eADF4 has been one, if not the only recombinant spidroin used for hydrogel formation so far. Low concentrations of potassium phosphate $(<300 \mathrm{mM})$ neutralize the coulombic repulsion between the negatively charged glutamates of eADF4 and lead to self-assembly of eADF4 into nanofibrils (Figure 4(B)). AFM analysis revealed an average height of $3.3 \pm 1 \mathrm{~nm}$ for air-dried silk 
fibrils, which reflects dimensions similar to that of amyloid-like fibrils [58]. FT-IR spectroscopy and $X$-ray diffraction patterns revealed the presence of an amyloid-like cross- $\beta$ structure in which the $\beta$-sheets are hydrogen-bonded and perpendicular to the fiber axis. The nanofibres appear to be semi-flexible with a persistence length in the same order of magnitude as their length. Many of the nanofibers also seem to assemble into branched structures by physical crosslinking (hydrophobic interactions) resulting in hydrogel formation-a hierarchically spanning network that ultimately immobilizes solvating water [59]. The self-assembled hydrogels were disrupted by agitation or shearing. Chemical cross-linking of the hydrogels $(10 \mathrm{mg} / \mathrm{mL}$ protein $)$ with ammonium peroxodisulphate and tris(2,2'-bipyridyl)dichlororuthenium(II) (a light-inducible cross-linker) yielded stable hydrogels with linear material response and much greater modulus and strength [59]. Since the spider silk hydrogels are stable over weeks and have a high elastic modulus even at low volume fractions, they are well suited for many different tissue engineering applications [60].

\subsection{Spheres Made of Recombinant Silk Proteins}

It is possible to produce spheres from recombinant spidroins by a couple of methods either through the relative hydropathies of the solvent and protein or through a salting out process. The first method was used for engineered spidroins based on MaSp1 of $N$. clavipes comprising between 1 and 6 repeating modules. In these spidroins the $\beta$-sheet content increased with the repetition number of alanine-rich blocks, while sphere formation was found to be related to the solvent environment, with sphere formation occurring with shorter proteins in water rather than in isopropanol [61]. The second method was performed with eADF4 which solely forms microspheres above a critical potassium phosphate buffer concentration (Figure 4(B)). Sphere formation follows a salting-out mechanism which can be considered a liquid-liquid phase separation. A nucleus is formed within the protein-rich phase, which induces a structural transition in the associated proteins followed by growth of the microspheres [53]. Spherical growth stops when the protein concentration in the protein-rich phase is below the equilibrium of solubility. Hence, the sphere diameter does not increase further. This model is supported by the fact that sphere size $(250 \mathrm{~nm}$ to $3 \mu \mathrm{m})$ depends on protein concentration and mixing conditions [62]. Solid microspheres reveal a smooth surface in SEM imaging, and FT-IR spectroscopy confirmed a high content of $\beta$-sheet structure similar to that of nanofibrils [53].

The obtained microspheres represent a new class of materials with many possible applications, e.g., as drug-delivery systems [63-65]. The soluble unfolded form of eADF4 is prone to interacting with hydrophobic surfaces, thus one possible application is to encapsulate water insoluble drugs (as shown with the model drug $\beta$-carotene). Firstly, soluble eADF4 leads to colloidal stabilization of $\beta$-carotene particles, and upon inducing microsphere formation $\beta$-carotene loaded eADF4 microspheres form. Digestion with intestinal fluids resulted in degradation of eADF4 protein microspheres and in subsequent $\beta$-carotene release, whereas the microspheres remain intact in gastric fluids. This sort of controlled release highlights the potential use of the silk spheres as drug delivery vehicles, remaining intact in the stomach and releasing the encapsulated drug in the small intestine [64]. Alternatively, the spheres can be used to encapsulate water soluble drugs. Small water soluble molecules with positive net-charge can diffuse into the negatively charged spider silk protein matrix driven by electrostatic interactions. Several model drugs were applied, and loading efficiencies 
were determined in dependence of drug molecule properties such as partition coefficient and dissociation constant. Further, loading efficiencies, release kinetics and biodegradation of the silk protein carriers have been investigated indicating that spider silk spheres have a potential as drug carriers where physical toughness is needed in combination with slow biodegradation [63].

\subsection{Capsules Made of Recombinant eADF4}

The amphiphilic character of engineered spider silk proteins causes spontaneous assembly at interfaces such as air/water or organic solvents/water [55,56,66]. Emulsification of eADF4 aqueous solution in toluene lead to rapid formation of micrometre sized capsules (Figure 4(A)). This process is only directed by protein diffusion, and $\beta$-sheet-rich structures form upon interaction with toluene [67]. The entire process is finished in less than 30 seconds yielding mechanically stable capsules that could be transferred back into aqueous solutions by centrifugation. This fast and efficient method of capsule formation is suitable for the encapsulation of high molecular weight active ingredients. The size of the microcapsules $(1-30 \mu \mathrm{m})$ can be conveniently controlled by adjusting the emulsion droplet size through changes in the emulsion shear rate. Since the capsules are porous (MW cut-off of $c a .27 \mathrm{kDa}$ ), small molecules can freely diffuse through the membrane. The release of active substances from such capsules can be triggered by limited proteolysis of the spidroins $[67,68]$.

Owing to material strength, biocompatibility and constrained degradation or release behavior spider silk capsules similar to microspheres have a high potential for the development of targeted drug-delivery systems [69].

\subsection{Films Made of Recombinant Spidroins}

Films can be cast from either aqueous or organic solutions of recombinant spidroins upon evaporation of the solvent. Commonly used solvents are aqueous buffers, HFIP, and formic acid. Several recombinant spidroins have been used to cast films [70-72]. The secondary structure of the protein film cast from HFIP solution is mostly $\alpha$-helical and random coil [71], similar to silkworm fibroin films cast from the same solvent or aqueous solution [73-75]. In contrast, films prepared from formic acid solutions are rich in $\beta$-sheet structure [74-76]. Post-treatment of the $\alpha$-helical/random coil-rich films by methanol or by kosmotropic phosphate ions leads to protein dehydration and induces a $\beta$-sheet-rich structure formation [70,71,76]. The as-cast films are smooth, and the post-processing increases the surface roughness [71,72]. Strikingly, only $\beta$-sheet rich films are stable in water and are even resistant to dissolution in very strong protein denaturing agents such as $8 \mathrm{M}$ urea or $6 \mathrm{M}$ guanidinium chloride, thus approaching the chemical stability of natural dragline silk fibres. Generally, increase in the $\beta$-sheet content leads to an increase in the elastic modulus, but a decrease in elasticity. The mechanical properties of spider silk films can be rendered more elastic by the relative humidity of the environment or the addition of hygroscopic plasticizers like glycerol, which alter intermolecular interactions. As an example, a content of $40 \% \mathrm{w} / \mathrm{v}$ glycerol increases the elasticity of a eADF4 film about tenfold, accompanied by a tenfold decrease in elastic modulus and a slight decrease in strength [65]. 


\section{Modification of Recombinant Spider Silk Proteins: Generation of Novel Functional Polymers}

Today's recombinant spider silk proteins are prevalently based on dragline sequence motifs such as poly-alanine, GGX and GPGXX. Apart from silk proteins solely based on dragline silk sequences, chemical as well as genetic modifications enable a fine tuning of the properties as well as the potential applications of the modified proteins.

\subsection{Chemical Modification of Recombinant Spider Silk Proteins}

Strategies for chemical modification of proteins are nowadays well established and allow efficient targeting of nucleophilic and electrophilic groups to amino acid side chains under mild physiological conditions [77,78]. Recent developments concerning the incorporation of non-natural amino acids, native chemical ligation and bio-orthogonal chemistries have expanded the possibilities for site-specific modifications [79,80]. Although the amino acid composition of silk proteins differs significantly from common globular proteins, comprising prevalently non-reactive alanine and glycine residues (>50\%) [29], the presence of carboxyl-terminated glutamic acid and aspartic acid, and hydroxyl-terminated serine and tyrosine residues permits the utilization of a broad range of chemical reactions. In contrast to modifying globular proteins, chemically altering silk proteins is simplified by the intrinsically unfolded nature of the core domain of spidroins in aqueous solution. The structural state of spidroins allows chemical modifications under harsh conditions, for example, in organic solvents, at high temperatures and in the presence of metal catalysts or initiators of polymerization [81-83]. The modifications of a solubilized spidroin or modification of processed spidroins (e.g., cast films) can be envisioned and achieved (Scheme 1). Coupling in solution is convenient for the incorporation of small functional molecules into bulk material. Coupling after silk processing is valuable for immobilization of larger molecules e.g., sensitive enzymes, where the activity has to be preserved for further function. eADF4 comprises one glutamic acid residue per repetitive unit, which in addition to the C-terminus can be modified through the carboxylic group (Scheme 1(A)). This has been demonstrated through carbodiimide/N-hydroxysuccinimide (EDC/NHS) mediated coupling of the model enzyme $\beta$-galactosidase on film surfaces made of eADF4. Fluorescein-5-isothiocyanate, has also been anchored on eADF4 film's surface via an ethylenediamine linker using carbodiimide activation [70].

An alternative to chemical modification of existing reactive side chains in the protein is the introduction of a natural reactive group by genetic engineering that does not occur in the original protein. eADF4 has been modified by the introduction of cysteine containing modules using two independent routes. One possibility is the modification of the basic repeating module of eADF4 replacing a serine residue with a cysteine residue. In this way it is possible to add this new $\mathrm{C}^{*}$ module to either end of the existing protein. An alternative is an $\mathrm{N}$-terminal tag consisting of a flexible peptide chain which includes a cysteine residue. The cysteine containing proteins can be chemically modified through the thiol group with high specificity (Scheme 1). Specific modifications have been demonstrated by coupling of fluorescein-maleimide in aqueous buffer. Films of the protein have also been functionalized with maleimide modified gold nanoparticles with the aim of developing solid phase catalysts or conductive materials. Immobilization of enzymes on films has been shown through the immobilization of $\beta$-galactosidase, which remains functional on the surface, demonstrating that these films could be engineered as novel biosensors for applications in life sciences [84]. 
Scheme 1. Modification of films made of spidroins; (A) Glutamic acid residues within the natural sequence can be activated by EDC/NHS reagents and subsequently modified by various primary amines [70]; Cysteine variants of engineered spidroins (not naturally occurring) allow coupling through maleimide chemistry. Fluorescence labels, functional molecules like biotin, active enzymes and gold nanoparticle have been utilized for film functionalization [84]; (B) Two strategies for preparation of functionalized spidroin films: chemical modification of the protein in solution followed by film casting; or casting followed by chemical modification allowing the functionalization of the film surface [84,105].
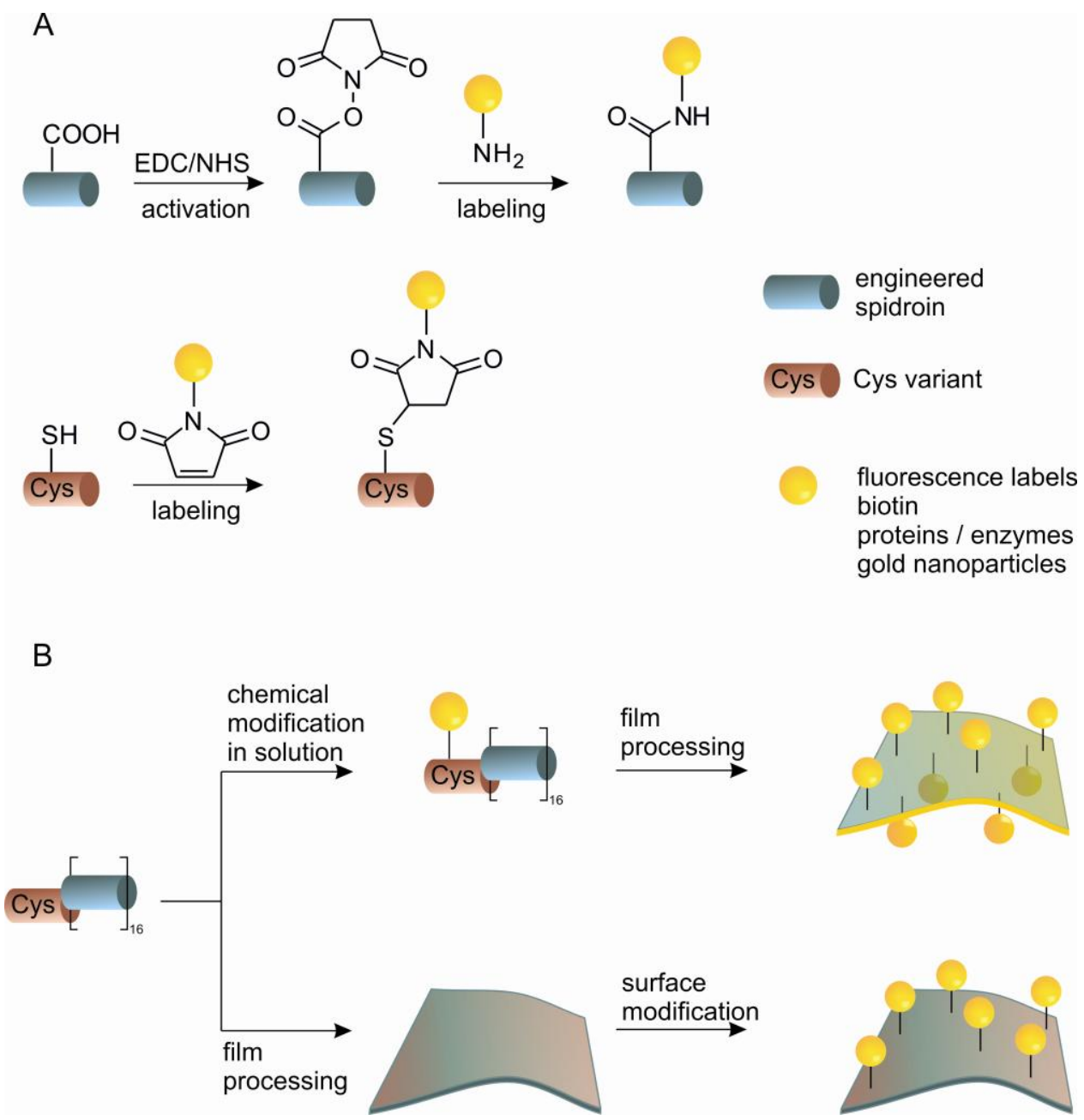

\subsection{Genetic Engineering: Silk Hybrid Proteins}

Apart from chemical approaches, the functional features of recombinant spider silk proteins can be expanded on a molecular level by fusing the silk sequence with the sequence of a functional peptide or protein. Such silk hybrids carry new integral functionalities avoiding post-translational chemical modification steps, which could be assumed as a drawback in certain applications, (e.g., in biomedicine or pharmacy) due to the potential toxicity of some reagents.

Use of recombinant spider silk chimeras in the field of drug delivery is feasible based on the biodegradability and biocompatibility of the silk unit. Poly (L-lysine) is a biodegradable cationic polymer which interacts with DNA through electrostatic interaction. Plasmid DNA (pDNA) complexes with spider silk-poly(L-lysine) hybrids [85] have been shown to deliver genes to human embryonic 
kidney (HEK) cells, since these complexes assemble into particles (300-500 nm) suitable for cellular uptake. However, the transfection efficiency is not high enough in this approach to reflect a new gene delivery system [85]. To improve the delivery efficiency, silk-poly(L-lysine) hybrids have been developed that incorporate cell binding motifs to aid in the cellular uptake of the pDNA complexes $[69,86]$. Recombinant silk proteins containing one or more RGD sequences in addition to the poly(L-lysine) region, containing 30 lysines, have been developed for gene delivery. The RGD sequences are used to promote integrin-mediated endocytosis. By comparing uptake between HeLa and HEK cell lines it has been demonstrated that the presence of two or more RGD sequences improves the uptake of complexed pDNA especially into cells expressing integrins, such as HeLa cells. A recombinant silk protein containing 11 RGD sequences as well as the poly(L-lysine) showed the highest transfection efficiency [86].

Organic-inorganic hybrid materials incorporating spider silk have been envisioned for some applications. In nature such hybrid materials are typically formed through biomineralization processes, such as those that form the silica skeletal architectures in diatoms, which are characterized by remarkable morphological and nanostructural details [87]. Silaffins are low molecular weight proteins involved in silica formation in diatoms. In vitro studies using a peptide derived from the repetitive motif found in silaffin proteins (known as the R5 peptide) demonstrated that this peptide promotes and regulates silica formation at neutral $\mathrm{pH}$ [88]. Genetically engineered chimeric proteins based on $N$. clavipes MaSp1 and the R5 peptide are capable of both self-assembly and biomineralization. This fusion protein has been used to electrospin fibers and to cast films from HFIP. Incubation of the fibers and films with tetramethoxysilane led to silica formation on top of the silk template [89]. The influence of these silk-silica composite systems on osteogenesis was evaluated with human mesenchymal stem cells (hMSCs) subjected to osteogenic differentiation. The presence of the silica in the silk films influenced osteogenic gene expression and early bone formation, as calcium containing deposits were observed on silk films with silica [90].

Another approach for using silk in bone formation has been to mineralize it with hydroxyapatite. Hydroxyapatite (HA), $\mathrm{Ca}_{10}\left(\mathrm{PO}_{4}\right)_{6}(\mathrm{OH})_{2}$, is an important inorganic material in bone and dentin [91]. Acidic glycoproteins, such as the dentin matrix protein 1 [92], are involved in the nucleation and oriented crystallisation of HA, which is a pre-requisite for the remarkable toughness and hardness of these tissues. Genetically engineered chimeric proteins, based on sequences of $N$. clavipes MaSp1 and the dentin matrix protein 1, are capable of both self-assembly and biomineralization [93]. Incubation of the films in simulated body fluid led to the growth of hydroxyapatite crystals on the surface of the film, whereas films cast from the control protein without the dentin matrix protein 1 domain did not induce biomineralization [93].

\subsection{Silk Inspired Synthetic Polymers}

The most common silk peptide motifs incorporated into peptide-polymer hybrids are the $\beta$-sheet sequences relevant for $\beta$-sheet formation. Short sequences, are conveniently accessible by common solid phase synthesis and already display desirable properties [94]. Poly(alanylglycine) and poly(alanine) present in spider silk proteins are responsible for crystallinity and hence stiffness of fibers made thereof. A number of silk-inspired polymers containing blocks of $\beta$-sheet-forming 
peptides $[\mathrm{GA}]_{\mathrm{n}}$ or $(\mathrm{A})_{\mathrm{nn}}$ and flexible linkers like PEG [poly(ethylene glycol)] have been reported [94-98]. The Sogah group has published the most comprehensive studies of silk-inspired polymers [99,100]. Multiblock copolymers containing either GAGA tetrapeptides or (A) 4-6 $_{\text {peptides }}$ coupled with a flexible PEG spacer were prepared, and mechanical properties of the cast films from HFIP or trifluoroethanol solutions were compared. For all designed polymers, a microphase-separated morphology was observed with $20-50 \mathrm{~nm} \beta$-sheet peptide domains dispersed in a continuous PEG phase. However, films processed from poly(alanine) block copolymer solutions revealed better mechanical properties (elastic modulus $\sim 310 \mathrm{MPa}$, tensile strength $\sim 17 \mathrm{MPa}$, elongation at break $\sim 26 \%$ ) than those of the equivalent polymer containing the GAGA tetrapeptide [101]. Another approach has been to take the same tetrapeptide and attach C12 alkyl tails on both ends [102]. It has been shown that the tetrapeptide adopts a $\beta$-sheet structure in fibrillar networks in various organic solvents. The density of these networks results in the formation of organogels and also zerogels once the solvent has been removed. Additionally, by varying the length of the alkyl tail, or its composition, it is possible to mediate the organogel formed from such molecules [103].

The molecular structure of spider silk has inspired a number of researchers to apply the same basic self-assembly concepts to non-natural systems. One such concept has been to develop a poly-ion complex (PIC) from oppositely charged polyelectrolytes that, when complexed, precipitate out of aqueous solution due to charge neutralization. By using both poly-lysine and poly-glutamic acid it is possible to spin a silk-like thread that can be drawn from a dope solution and passed through a dehydration bath. These fibers possess a high extensibility, and as these fibers are stretched they become stronger, however, not as strong as spider silk. These fibers have a $\beta$-sheet structure, and it is proposed that excess of poly-lysine initiates a disordered structure giving the threads their high extensibility, reminiscent of the spider silk structure [104].

\section{Outlook and Conclusion}

There are now a range of recombinant spider silk proteins being studied that are produced by a variety of host organisms and at sufficient quantities, to allow the exploration of potential material's applications. The physical properties of spider silks highlight the potential for threads to act as high performance fibers. The main hurdle now for this area is the development of suitable spinning technologies to reproducibly form threads with properties similar to that of the natural material. Spidroins have also been shown to be versatile proteins with the capability to be processed into a wide range of non-fibrous morphologies. Combined with their natural biocompatibility and low immune response they are ideal for e.g., biomedical applications. Research is well underway into the fields of cell culture and drug delivery applications of these materials. Additionally, the understanding of the molecular structure of silks has inspired a range of research utilizing the repeating modules of silk in combination with other chemical motifs to develop novel materials. Lastly, the molecular assembly process of silk has inspired research into materials based on these concepts in an attempt to take advantage of similar assembly mechanics to produce new high performance materials. The research area of spider silk and its various applications will likely continue to be an interesting and competitive field of research for a long time to come. 


\section{Acknowledgements}

We acknowledge the DFG SCHE 603/4-3 and SFB 840 TP8 for funding.

\section{References}

1. Gerritsen, V.B. The tiptoe of an airbus. Prot. Spotlight Swiss Prot. 2002, 24, 1-2.

2. Heim, M.; Romer, L.; Scheibel, T. Hierarchical structures made of proteins.he complex architecture of spider webs and their constituent silk proteins. Chem. Soc. Rev. 2010, 39, 156-164.

3. Sutherland, T.D.; Young, J.H.; Weisman, S.; Hayashi, C.Y.; Merritt, D.J. Insect silk: One name, many materials. Ann. Rev. Entomol. 2010, 55, 171-188.

4. Blackledge, T.A.; Scharff, N.; Coddington, J.A.; Szuts, T.; Wenzel, J.W.; Hayashi, C.Y.; Agnarsson, I. Reconstructing web evolution and spider diversification in the molecular era. Proc. Natl. Acad. Sci. USA 2009, 106, 5229-5234.

5. Bunning, T.J.; Jiang, H.; Adams, W.W.; Crane, R.L.; Farmer, B.; Kaplan, D. Applications of Silk. In Silk Polymers-Materials Science and Biotechnology; Kaplan, D., Adams, W.W., Farmer, B., Viney, C., Eds.; American Chemical Society: Washington, DC, USA, 1994; Volume 544, pp. 353-358.

6. Gosline, J.M.; Guerette, P.A.; Ortlepp, C.S.; Savage, K.N. The mechanical design of spider silks: From fibroin sequence to mechanical function. J. Exp. Biol. 1999, 202, 3295-3303.

7. Rising, A.; Hjalm, G.; Engstrom, W.; Johansson, J. N-terminal nonrepetitive domain common to dragline, flagelliform, and cylindriform spider silk proteins. Biomacromolecules 2006, 7 , 3120-3124.

8. Rising, A.; Nimmervoll, H.; Grip, S.; Fernandez-Arias, A.; Storckenfeldt, E.; Knight, D.P.; Vollrath, F.; Engstrom, W. Spider silk proteins-mechanical property and gene sequence. Zoolog. Sci. 2005, 22, 273-281.

9. Ayoub, N.A.; Garb, J.E.; Tinghitella, R.M.; Collin, M.A.; Hayashi, C.Y. Blueprint for a high-performance biomaterial: Full-length spider dragline silk genes. Plos One 2007, 2, e514.

10. Sponner, A.; Unger, E.; Grosse, F.; Weisshart, K. Conserved C-termini of spidroins are secreted by the major ampullate glands and retained in the silk thread. Biomacromolecules 2004, 5, 840-845.

11. $\mathrm{Xu}, \mathrm{M}$; Lewis, R.V. Structure of a protein superfiber-Spider dragline silk. Proc. Natl. Acad. Sci. USA 1990, 87, 7120-7124.

12. Sponner, A.; Schlott, B.; Vollrath, F.; Unger, E.; Grosse, F.; Weisshart, K. Characterization of the protein components of Nephila clavipes dragline silk. Biochemistry 2005, 44, 4727-4736.

13. Lawrence, B.A.; Vierra, C.A.; Mooref, A.M.F. Molecular and mechanical properties of major ampullate silk of the black widow spider, Latrodectus hesperus. Biomacromolecules 2004, 5, 689-695.

14. Hu, X.; Vasanthavada, K.; Kohler, K.; McNary, S.; Moore, A.M.F.; Vierra, C.A. Molecular mechanisms of spider silk. Cell. Mol. Life Sci. 2006, 63, 1986-1999. 
15. Colgin, M.A.; Lewis, R.V. Spider minor ampullate silk proteins contain new repetitive sequences and highly conserved non-silk-like "spacer regions". Prot. Sci. 1998, 7, 667-672.

16. Gatesy, J.; Hayashi, C.; Motriuk, D.; Woods, J.; Lewis, R. Extreme diversity, conservation, and convergence of spider silk fibroin sequences. Science 2001, 291, 2603-2605.

17. Huemmerich, D.; Scheibel, T.; Vollrath, F.; Cohen, S.; Gat, U.; Ittah, S. Novel assembly properties of recombinant spider dragline silk proteins. Curr. Biol. 2004, 14, 2070-2074.

18. Grubb, D.T.; Jelinski, L.W. Fiber morphology of spider silk: The effects of tensile deformation. Macromolecules 1997, 30, 2860-2867.

19. Riekel, C.; Muller, M.; Vollrath, F. In situ X-ray diffraction during forced silking of spider silk. Macromolecules 1999, 32, 4464-4466.

20. Du, N.; Liu, X.Y.; Narayanan, J.; Li, L.A.; Lim, M.L.M.; Li, D.Q. Design of superior spider silk: From nanostructure to mechanical properties. Biophys. J. 2006, 91, 4528-4535.

21. Kummerlen, J.; van Beek, J.D.; Vollrath, F.; Meier, B.H. Local structure in spider dragline silk investigated by two-dimensional spin-diffusion nuclear magnetic resonance. Macromolecules 1996, 29, 2920-2928.

22. Simmons, A.H.; Michal, C.A.; Jelinski, L.W. Molecular orientation and two-component nature of the crystalline fraction of spider dragline silk. Science 1996, 271, 84-87.

23. Jenkins, J.E.; Creager, M.S.; Lewis, R.V.; Holland, G.P.; Yarger, J.L. Quantitative correlation between the protein primary sequences and secondary structures in spider dragline silks. Biomacromolecules 2010, 11, 192-200.

24. Termonia, Y. Molecular modeling of spider silk elasticity. Macromolecules 1994, 27, 7378-7381.

25. Hayashi, C.Y.; Lewis, R.V. Spider flagelliform silk: Lessons in protein design, gene structure, and molecular evolution. Bioessays 2001, 23, 750-756.

26. Ohgo, K.; Kawase, T.; Ashida, J.; Asakura, T. Solid-state NMR analysis of a peptide (Gly-Pro-Gly-Gly-Ala)(6)-Gly derived from a flagelliform silk sequence of Nephila clavipes. Biomacromolecules 2006, 7, 1210-1214.

27. Hayashi, C.Y.; Shipley, N.H.; Lewis, R.V. Hypotheses that correlate the sequence, structure, and mechanical properties of spider silk proteins. Int. J. Biol. Macromol. 1999, 24, 271-275.

28. Jenkins, J.E.; Creager, M.S.; Butler, E.B.; Lewis, R.V.; Yarger, J.L.; Holland, G.P. Solid-state NMR evidence for elastin-like beta-turn structure in spider dragline silk. Chem. Commun. 2010, 46, 6714-6716.

29. Heim, M.; Keerl, D.; Scheibel, T. Spider silk: From soluble protein to extraordinary fiber. Angew. Chem.-Int. Ed. 2009, 48, 3584-3596.

30. Vehoff, T.; Glisovic, A.; Schollmeyer, H.; Zippelius, A.; Salditt, T. Mechanical properties of spider dragline silk: Humidity, hysteresis, and relaxation. Biophys. J. 2007, 93, 4425-4432.

31. Teule, F.; Cooper, A.R.; Furin, W.A.; Bittencourt, D.; Rech, E.L.; Brooks, A.; Lewis, R.V. A protocol for the production of recombinant spider silk-like proteins for artificial fiber spinning. Nat. Protoc. 2009, 4, 341-355.

32. Arcidiacono, S.; Mello, C.; Kaplan, D.; Cheley, S.; Bayley, H. Purification and characterization of recombinant spider silk expressed in Escherichia coli. Appl. Microbiol. Biotechnol. 1998, 49, 31-38. 
33. Candelas, G.C.; Arroyo, G.; Carrasco, C.; Dompenciel, R. Spider silk glands contain a tissue-specific Alanine transfer-RNA that accumulates in vitro in response to the stimulus for slk protein-synthesis. Dev. Biol. 1990, 140, 215-220.

34. Xia, X.X.; Qian, Z.G.; Ki, C.S.; Park, Y.H.; Kaplan, D.L.; Lee, S.Y. Native-sized recombinant spider silk protein produced in metabolically engineered Escherichia coli results in a strong fiber. Proc. Natl. Acad. Sci. USA 2010, 107, 14059-14063.

35. Lazaris, A.; Arcidiacono, S.; Huang, Y.; Zhou, J.F.; Duguay, F.; Chretien, N.; Welsh, E.A.; Soares, J.W.; Karatzas, C.N. Spider silk fibers spun from soluble recombinant silk produced in mammalian cells. Science 2002, 295, 472-476.

36. Zhang, Y.S.; Hu, J.H.; Miao, Y.G.; Zhao, A.C.; Zhao, T.F.; Wu, D.Y.; Liang, L.F.; Miikura, A.M.; Shiomi, K.; Kajiura, Z.; Nakagaki, M. Expression of EGFP-spider dragline silk fusion protein in BmN cells and larvae of silkworm showed the solubility is primary limit for dragline proteins yield. Mol. Biol. Rep. 2008, 35, 329-335.

37. Wen, H.X.; Lan, X.Q.; Zhang, Y.S.; Zhao, T.F.; Wang, Y.J.; Kajiura, Z.; Nakagaki, M. Transgenic silkworms (Bombyx mori) produce recombinant spider dragline silk in cocoons. Mol. Biol. Rep. 2010, 37, 1815-1821.

38. Heim, M.; Ackerschott, C.B.; Scheibel, T. Characterization of recombinantly produced spider flagelliform silk domains. J. Struct. Biol. 2010, 170, 420-425.

39. Teule, F.; Furin, W.A.; Cooper, A.R.; Duncan, J.R.; Lewis, R.V. Modifications of spider silk sequences in an attempt to control the mechanical properties of the synthetic fibers. J. Mater. Sci. 2007, 42, 8974-8985.

40. Zhou, Y.T.; Wu, S.X.; Conticello, V.P. Genetically directed synthesis and spectroscopic analysis of a protein polymer derived from a flagelliform silk sequence. Biomacromolecules 2001, 2, 111-125.

41. Scheller, J.; Guhrs, K.H.; Grosse, F.; Conrad, U. Production of spider silk proteins in tobacco and potato. Nat. Biotechnol. 2001, 19, 573-577.

42. Barr, L.A.; Fahnestock, S.R.; Yang, J.J. Production and purification of recombinant DP1B silk-like protein in plants. Mol. Breed. 2004, 13, 345-356.

43. Yang, J.J.; Barr, L.A.; Fahnestock, S.R.; Liu, Z.B. High yield recombinant silk-like protein production in transgenic plants through protein targeting. Transgenic Res. 2005, 14, 313-324.

44. Huemmerich, D.; Helsen, C.W.; Quedzuweit, S.; Oschmann, J.; Rudolph, R.; Scheibel, T. Primary structure elements of spider dragline silks and their contribution to protein solubility. Biochemistry 2004, 43, 13604-13612.

45. Rammensee, S.; Slotta, U.; Scheibel, T.; Bausch, A.R. Assembly mechanism of recombinant spider silk proteins. Proc. Natl. Acad. Sci. USA 2008, 105, 6590-6595.

46. Eisoldt, L.; Hardy, J.G.; Heim, M.; Scheibel, T.R. The role of salt and shear on the storage and assembly of spider silk proteins. J. Struct. Biol. 2010, 170, 413-419.

47. Exler, J.H.; Hummerich, D.; Scheibel, T. The amphiphilic properties of spider silks are important for spinning. Angew. Chem.-Int. Ed. 2007, 46, 3559-3562.

48. Hagn, F.; Eisoldt, L.; Hardy, J.G.; Vendrely, C.; Coles, M.; Scheibel, T.; Kessler, H. A highly conserved spider silk domain acts as a molecular switch that controls fibre assembly. Nature 2010, 465, 239-242. 
49. Hagn, F.; Thamm, C.; Scheibel, T.; Kessler, H. pH-dependent dimerization and salt-dependent stabilization of the N-terminal domain of spider dragline silk-implications for fiber formation. Angew. Chem. Int. Ed. 2011, 50, 310-313.

50. Scheibel, T. Spider silks: Recombinant synthesis, assembly, spinning, and engineering of synthetic proteins. Microb. Cell Fact. 2004, 3, 14.

51. Seidel, A.; Liivak, O.; Calve, S.; Adaska, J.; Ji, G.D.; Yang, Z.T.; Grubb, D.; Zax, D.B.; Jelinski, L.W. Regenerated spider silk: Processing, properties, and structure. Macromolecules 2000, 33, 775-780.

52. Cacace, M.G.; Landau, E.M.; Ramsden, J.J. The Hofmeister series: Salt and solvent effects on interfacial phenomena. Q. Rev. Biophys. 1997, 30, 241-277.

53. Slotta, U.K.; Rammensee, S.; Gorb, S.; Scheibel, T. An engineered spider silk protein forms microspheres. Angew. Chem.-Int. Ed. 2008, 47, 4592-4594.

54. Zhang, Y.; Cremer, P.S. Interactions between macromolecules and ions: The Hofmeister series. Curr. Opin. Chem. Biol. 2006, 10, 658-663.

55. Geisler, M.; Pirzer, T.; Ackerschott, C.; Lud, S.; Garrido, J.; Scheibel, T.; Hugel, T. Hydrophobic and Hofmeister effects on the adhesion of spider silk proteins onto solid substrates: An AFM-based single-molecule study. Langmuir 2008, 24, 1350-1355.

56. Horinek, D.; Serr, A.; Geisler, M.; Pirzer, T.; Slotta, U.; Lud, S.Q.; Garrido, J.A.; Scheibel, T.; Hugel, T.; Netz, R.R. Peptide adsorption on a hydrophobic surface results from an interplay of solvation, surface, and intrapeptide forces. Proc. Natl. Acad. Sci. USA 2008, 105, 2842-2847.

57. Askarieh, G.; Hedhammar, M.; Nordling, K.; Saenz, A.; Casals, C.; Rising, A.; Johansson, J.; Knight, S.D. Self-assembly of spider silk proteins is controlled by a $\mathrm{pH}$-sensitive relay. Nature 2010, 465, 236-239.

58. Slotta, U.; Hess, S.; Spiess, K.; Stromer, T.; Serpell, L.; Scheibel, T. Spider silk and amyloid fibrils: A structural comparison. Macromol. Biosci. 2007, 7, 183-188.

59. Rammensee, S.; Huemmerich, D.; Hermanson, K.D.; Scheibel, T.; Bausch, A.R. Rheological characterization of hydrogels formed by recombinantly produced spider silk. Appl. Phys. A-Mater. Sci. Process. 2006, 82, 261-264.

60. Leal-Egana, A.; Scheibel, T. Silk-based materials for biomedical applications. Biotechnol. Appl. Biochem. 2010, 55, 155-167.

61. Rabotyagova, O.S.; Cebe, P.; Kaplan, D.L. Self-assembly of genetically engineered spider silk block copolymers. Biomacromolecules 2009, 10, 229-236.

62. Lammel, A.; Schwab, M.; Slotta, U.; Winter, G.; Scheibel, T. Processing conditions for the formation of spider silk microspheres. Chemsuschem 2008, 1, 413-416.

63. Lammel, A.; Schwab, M.; Hofer, M.; Winter, G.; Scheibel, T. Recombinant spider silk particles as drug delivery vehicles. Biomaterials 2011, 32, 2233-2240.

64. Liebmann, B.; Huemmerich, D.; Scheibel, T.; Fehr, M. Formulation of poorly water-soluble substances using self-assembling spider silk protein. Colloids Surface A-Phys. Chem. Eng. Asp. 2008, 331, 126-132.

65. Spiess, K.; Lammel, A.; Scheibel, T. Recombinant spider silk proteins for applications in biomaterials. Macromol. Biosci. 2010, 10, 998-1007. 
66. Zbilut, J.P.; Scheibel, T.; Huemmerich, D.; Webber, C.L.; Colafranceschi, M.; Giuliani, A. Spatial stochastic resonance in protein hydrophobicity. Phys. Lett. A 2005, 346, 33-41.

67. Hermanson, K.D.; Huemmerich, D.; Scheibel, T.; Bausch, A.R. Engineered microcapsules fabricated from reconstituted spider silk. Adv. Mater. 2007, 19, 1810-1815.

68. Hermanson, K.D.; Harasim, M.B.; Scheibel, T.; Bausch, A.R. Permeability of silk microcapsules made by the interfacial adsorption of protein. Phys. Chem. Chem. Phys. 2007, 9, 6442-6446.

69. Numata, K.; Kaplan, D.L. Silk-based delivery systems of bioactive molecules. Adv. Drug Deliv. Rev. 2010, 62, 1497-1508.

70. Huemmerich, D.; Slotta, U.; Scheibel, T. Processing and modification of films made from recombinant spider silk proteins. Appl. Phys. A-Mater. Sci. Process. 2006, 82, 219-222.

71. Slotta, U.; Tammer, M.; Kremer, F.; Koelsch, P.; Scheibel, T. Structural analysis of spider silk films. Supramol. Chem. 2006, 18, 465-471.

72. Metwalli, E.; Slotta, U.; Darko, C.; Roth, S.V.; Scheibel, T.; Papadakis, C.M. Structural changes of thin films from recombinant spider silk proteins upon post-treatment. Appl. Phys. A-Mater. Sci. Process. 2007, 89, 655-661.

73. Zhao, C.; Yao, J.; Masuda, H.; Kishore, R.; Asakura, T. Structural characterization and artificial fiber formation of Bombyx mori silk fibroin in hexafluoro-iso-propanol solvent system. Biopolymers 2003, 69, 253-259.

74. Um, I.C.; Kweon, H.Y.; Park, Y.H.; Hudson, S. Structural characteristics and properties of the regenerated silk fibroin prepared from formic acid. Int. J. Biol. Macromol. 2001, 29, 91-97.

75. Vasconcelos, A.; Freddi, G.; Cavaco-Paulo, A. Biodegradable materials based on silk fibroin and keratin. Biomacromolecules 2008, 9, 1299-1305.

76. Spiess, K.; Lammel, A.; Scheibel, T. Recombinant spider silk proteins for applications in biomaterials. Macromol. Biosci. 2010, 10, 998-1007.

77. Thordarson, P.; Le Droumaguet, B.; Velonia, K. Well-defined protein-polymer conjugates-synthesis and potential applications. Appl. Microb. Biotechnol. 2006, 73, 243-254.

78. Carrico, I.S. Chemoselective modification of proteins: Hitting the target. Chem. Soc. Rev. 2008, 37, 1423-1431.

79. Hackenberger, C.P.; Schwarzer, D. Chemoselective ligation and modification strategies for peptides and proteins. Angew. Chem. Int. Ed. Engl. 2008, 47, 10030-10074.

80. Sletten, E.M.; Bertozzi, C.R. Bioorthogonal chemistry: Fishing for selectivity in a sea of functionality. Angew. Chem. Int. Ed. Engl. 2009, 48, 6974-6998.

81. Tamada, Y. Sulfation of silk fibroin by chlorosulfonic acid and the anticoagulant activity. Biomaterials 2004, 25, 377-383.

82. Gotoh, K.; Izumi, H.; Kanamoto, T.; Tamada, Y.; Nakashima, H. Sulfated fibroin, a novel sulfated peptide derived from silk, inhibits human immunodeficiency virus replication in vitro. Biosci. Biotechnol. Biochem. 2000, 64, 1664-1670.

83. Furuzono, T.; Ishihara, K.; Nakabayashi, N.; Tamada, Y. Chemical modification of silk fibroin with 2-methacryloyloxyethyl phosphorylcholine. II. Graft-polymerization onto fabric through 2-methacryloyloxyethyl isocyanate and interaction between fabric and platelets. Biomaterials 2000, 21, 327-333. 
84. Spiess, K.; Wohlrab, S.; Scheibel, T. Structural characterization and functionalization of engineered spider silk films. Soft Matter 2010, 6, 4168-4174.

85. Numata, K.; Subramanian, B.; Currie, H.A.; Kaplan, D.L. Bioengineered silk protein-based gene delivery systems. Biomaterials 2009, 30, 5775-5784.

86. Numata, K.; Hamasaki, J.; Subramanian, B.; Kaplan, D.L. Gene delivery mediated by recombinant silk proteins containing cationic and cell binding motifs. J. Control. Release 2010, 146, 136-143.

87. Hildebrand, M. Diatoms, biomineralization processes, and genomics. Chem. Rev. 2008, 108, 4855-4874.

88. Kroger, N.; Deutzmann, R.; Sumper, M. Polycationic peptides from diatom biosilica that direct silica nanosphere formation. Science 1999, 286, 1129-1132.

89. Foo, C.W.P.; Patwardhan, S.V.; Belton, D.J.; Kitchel, B.; Anastasiades, D.; Huang, J.; Naik, R.R.; Perry, C.C.; Kaplan, D.L. Novel nanocomposites from spider silk-silica fusion (chimeric) proteins. Proc. Natl. Acad. Sci. USA 2006, 103, 9428-9433.

90. Mieszawska, A.J.; Nadkarni, L.D.; Perry, C.C.; Kaplan, D.L. Nanoscale control of silica particle formation via silk-silica fusion proteins for bone regeneration. Chem. Mater. 2010, 22, 5780-5785.

91. Fratzl, P.; Gupta, H.S.; Paschalis, E.P.; Roschger, P. Structure and mechanical quality of the collagen-mineral nano-composite in bone. J. Mater. Chem. 2004, 14, 2115-2123.

92. He, G.; Dahl, T.; Veis, A.; George, A. Nucleation of apatite crystals in vitro by self-assembled dentin matrix protein, 1. Nat. Mater. 2003, 2, 552-558.

93. Huang, J.; Wong, C.; George, A.; Kaplan, D.L. The effect of genetically engineered spider silk-dentin matrix protein 1 chimeric protein on hydroxyapatite nucleation. Biomaterials 2007, 28, 2358-2367.

94. Van Hest, J.C.M. Biosynthetic-synthetic polymer conjugates. Polym. Rev. 2007, 47, 63-92.

95. Yao, J.R.; Xiao, D.H.; Chen, X.; Zhou, P.; Yu, T.Y.; Shao, Z.Z. Synthesis and solid-state secondary structure investigation of silk-proteinlike multiblock polymers. Macromolecules $\mathbf{2 0 0 3}$, 36, 7508-7512.

96. Smeenk, J.M.; Otten, M.B.; Thies, J.; Tirrell, D.A.; Stunnenberg, H.G.; van Hest, J.C. Controlled assembly of macromolecular beta-sheet fibrils. Angew. Chem. Int. Ed. Engl. 2005, 44, 1968-1971.

97. Smeenk, J.M.; Schon, P.; Otten, M.B.J.; Speller, S.; Stunnenberg, H.G.; van Hest, J.C.M. Fibril formation by triblock copolymers of silklike beta-sheet polypeptides and poly(ethylene glycol). Macromolecules 2006, 39, 2989-2997.

98. Zhou, C.C.; Leng, B.X.; Yao, J.R.; Qian, J.; Chen, X.; Zhou, P.; Knight, D.P.; Shao, Z.Z. Synthesis and characterization of multiblock copolymers based on spider dragline silk proteins. Biomacromolecules 2006, 7, 2415-2419.

99. Rathore, O.; Sogah, D.Y. Nanostructure formation through beta-sheet self-assembly in silk-based materials. Macromolecules 2001, 34, 1477-1486.

100. Rathore, O.; Sogah, D.Y. Self-assembly of beta-sheets into nanostructures by poly(alanine) segments incorporated in multiblock copolymers inspired by spider silk. J. Am. Chem. Soc. 2001, $123,5231-5239$. 
101. Sirichaisit, J.; Brookes, V.L.; Young, R.J.; Vollrath, F. Analysis of structure/property relationships in silkworm (Bombyx mori) and spider dragline (Nephila edulis) silks using Raman Spectroscopy. Biomacromolecules 2003, 4, 387-394.

102. Escuder, B.; Miravet, J.F. Silk-inspired low-molecular-weight organogelator. Langmuir 2006, 22, 7793-7797.

103. Iqbal, S.; Miravet, J.F.; Escuder, B. Biomimetic self-assembly of tetrapeptides into fibrillar networks and organogels. Eur. J. Org. Chem. 2008, 2008, 4580-4590.

104. Hachisu, M.; Ohkawa, K.; Yamamoto, H. Preparation of silk-like fibers designed by self-assembled ionic polypeptides. Macromol. Biosci. 2003, 3, 92-99.

105. Hardy, J.G.; Romer, L.M.; Scheibel, T.R. Polymeric materials based on silk proteins. Polymer 2008, 49, 4309-4327.

106. Sponner, A.; Vater, W.; Monajembashi, S.; Unger, E.; Grosse, F.; Weisshart, K. Composition and hierarchical organisation of a spider silk. PloS one 2007, 2, e998.

107. Augsten, K.; Muhlig, P.; Herrmann, C. Glycoproteins and skin-core structure in Nephila clavipes spider silk observed by light and electron microscopy. Scanning 2000, 22, 12-15.

108. van Beek, J.D.; Hess, S.; Vollrath, F.; Meier, B.H. The molecular structure of spider dragline silk: folding and orientation of the protein backbone. Proc. Natl. Acad. Sci. USA 2002, 99, 10266-10271.

109. Papadopoulos, P.; Solter, J.; Kremer, F. Hierarchies in the structural organization of spider silk-a quantitative model. Colloid Polym. Sci. 2009, 287, 231-236.

110. Eles, P.T.; Michal, C.A. Strain dependent local phase transitions observed during controlled supercontraction reveal mechanisms in spider silk. Macromolecules 2004, 37, 1342-1345.

111. Vollrath, F.; Porter, D. Silks as ancient models for modern polymers. Polymer 2009, 50, 5623-5632.

112. Nova, A.; Keten, S.; Pugno, N.M.; Redaelli, A.; Buehler, M.J. Molecular and nanostructural mechanisms of deformation, strength and toughness of spider silk fibrils. Nano Lett. 2010, 10, 2626-2634.

113. Glisovic, A.; Vehoff, T.; Davies, R.J.; Salditt, T. Strain dependent structural changes of spider dragline silk. Macromolecules 2008, 41, 390-398.

114. Vendrely, C.; Scheibel, T. Biotechnological production of spider-silk proteins enables new applications. Macromol. Biosci. 2007, 7, 401-409.

(C) 2011 by the authors; licensee MDPI, Basel, Switzerland. This article is an open access article distributed under the terms and conditions of the Creative Commons Attribution license (http://creativecommons.org/licenses/by/3.0/). 